\title{
Attempts innovative university education mode based on the thickness of foundation and large-caliber
}

\author{
Yao Pirong \\ Yibin University's School of Computer \& Information Engineering \\ Yibin, Sichuan province, China, 644000 \\ E-mail: 458468255@qq.com
}

\begin{abstract}
After the founding of New China, after the 1950s faculties adjustment、 recovery after the Cultural Revolution of the 1960s and the expansion of the early 21st century, higher education in China has entered the universal higher education historical reflection period in 2010 before and after; The goal of higher education is no longer so simple only for developing a "socialist production talent", the rapid development of the information age; you need people trained by colleges and universities with a wide range of adaptability. However, parents and students, and society does not practice on the value orientation and aspirations for higher education, this led to the educational services provided by the colleges and universities in a dilemma that needs of the community and the family, the needs of students. In recent years, many colleges and universities to continue to carry out the exploration of the mode of education in order to adapt to the needs of the parties, for professional education, the thick foundation liberal Education allows students more employment export a wider diameter.
\end{abstract}

Keywords-Higher Education Value; Changing goals of higher education in China; Professional education and liberal education; The resistance of the liberal education; "Thick foundation, wide caliber "education model attempts

The value orientation of higher education is to cultivate what students, or students into what kind of person. 1962 UNESCO Higher Education gives a definition: "Higher education refers to all types of education provided by the University, Faculty of Arts, Faculty of Science and Teachers College and other institutions, the basic entry requirements for the completion of secondary education."[1] That value orientation or educational goals by some experts call "liberal education", train people with extensive knowledge and elegance that allow students to get rid of the vulgar wake excellence. Experts may not any soul, but it can become a literate person. China given definition is: "a variety of professional education on the basis of secondary education."[2] This value orientation is sometimes also referred to as "professional education", higher education is to develop the education of senior specialists, with significant "pre-education" [3], which means that the value of higher education is mainly reflected in the social employment for students to prepare.

I. CHINA'S Higher EdUCATION VALUE ORIENTATION CHANGES
The course of development of Chinese higher education value orientation can be divided into the following different stages:

\section{A. The initial stage (1879-1920)}

In the true sense of Chinese modern university is St. John's University in Shanghai by the American Anglican Church was established in 1879, after which, funded by foreign churches run by University continued to appear in major cities; Christian in mainland China already has 13the university; Catholic only three universities of Beijing Fu Jen Catholic, Tianjin Jingu and Shanghai's Aurora ${ }^{[4]}$. University of the purpose of the church is to preach religious and the spread of Western culture and values, traditional western liberal Education higher education value orientation.

Chinese government-run earliest universities are the Northern School (1895), Anyang Public Universities (1896) and the Imperial Academy (1898). The Chinese governmentrun affairs of the modern university background, the Qing government to recognize the painful experience of education and scientific and technological backwardness after the failure of the Sino-Japanese War, funded the setting up of the university. The main objective of the government-run university church university similar but different, mainly in the more "pragmatic", highlighting the practical industrial training of technical personnel, emphasis on education, but not to study education.

The Church University this period trained many gurus, such as: LaOshe, BiNgxin, FaNgdongmei FeiXiaotong, HuangHua, LeiJieru, LuPing, and ZhouNan etc. Although many National University trained students are then useful to our country on all fronts, but its international influence and social status are not as the period church college graduates.

\section{B The development phase (1920-1949)}

1920 before and after, and are in urgent need to be political, economic, military personnel, under the impetus of the central and local military government, China's higher education has ushered in a new period of development, the provincial capital cities were founded National University and funded by the central or local government financed by non-governmental organizations or consortia of private universities. "211" or "985" universities now almost all the time to build up, which is characterized by both public and private, central and local, domestic and foreign co-exist.

In this period, the goal of higher education has the typical "dispersed", church universities remain liberal arts liberal 
education as the goal, the government-run and private universities in the goal is to service local government economic regime building.

\section{$C$ The faculties adjustment phase (1949-1976) and the recovery phase (1977-1998)}

After the founding of New China, the nation-building requires a large number of professionals, the main focus on the higher education is directly related to economic construction, especially in engineering and science and technology, education programs and is closely linked to the national economic construction plan. Almost all universities, colleges, whether funded nature first received as a stateowned them all industries, sectors or products to re-adjust the points, demolition, or the establishment of new professional schools, departments and professional, such as: tractor colleges, coal academy petroleum faculty, Institute of light institute, chemistry and chemical school, etc. After the adjustment of this faculty, China becomes a comprehensive university in the world, the countries with the least proportion of the Arts students and liberal arts education. At the time, however, the integration of the disciplines has become a major trend in the development of science. This large-scale the faculties' adjustment stems from the Chinese government to fundamentally change the university system, the original idea of the university and the University of Connotation is changed, higher education since been incorporated into the highly centralized management planning system ${ }^{[5]}$.

In quite a long time after that, the goal of higher education is to train professionals in all walks of life, equate to higher education in vocational education or pre-service education. This effect not only in higher education internal, but also profound impact on all aspects of Chinese society, especially the "learning to use" and "professional counterparts" deep-rooted in learners and employer.

After ten years of chaos, institutions of higher learning in China resumed the examination and enrollment, all colleges and universities to usher in a new period of development; social demand for talent is similar to the early days, so almost no change in educational goals. At this stage, the development of higher education in China is basically the tertiary institutions to recover based on the original, larger and become strong.

However, from 1995 onwards, the increasing pressure of college admissions, the reason is that after the reform and opening up, each family has on the enjoyment of the needs of higher education desire, with the accumulation of family economy, while those in the birth of the peak period (about 1980) born children to receive higher education's time; these are the popularization of higher education in China is imperative.

\section{The expansion phase (1999-2010)}

Beginning in 1999, China's higher education began largescale expansion of the scale of enrollment in 1998 from 1080 thousand to 6290 thousand in 2009 and 1977 to recruit 27 thousand. Colleges and universities to expand enrollment originally in order to adapt to the needs of the community to enjoy higher education, however, in the face of the poly rapidly increasing number of college graduates, the needs of the community has been unable to achieve unified enrollment and unified distribution like the planned economy era.

\section{LOCAL UNIVERSITIES NEED TO FACE THE PROBLEM ON} THE EDUCATIONAL GOALS AND VALUES

China's higher education from the elite towards popularization, with the wave of information technology and political transformation of the economic system, the social demand is no longer a kind of the competent some kind of professional expertise; demand has begun from the planned economy era, "specifically talent "to return to" extensive and elegant "the combined composite natural person.

\section{A. Countries, students, families among not consistent with} the goals of higher education in China

The functions of the university and its value orientation is related, explained by the UNESCO in 1962, the functions of the colleges and universities should be teaching, scientific research, social services, the three functions integrated ${ }^{[3]}$. Many parents and students, the university functions more is that vocational education or pre-education, the purpose of entering the University directly at employment. And, now there are a lot of agencies are based on the employment rate of university or professional college and professional rank reference for high school students apply for school or professional. Under the influence of the several thousand years of imperial culture, many families still think this is the only way to that is through the children to receive higher education let his son become a dragon to let his daughter become the phoenix, admitted to the civil service still holding this goal, it is hope that the children read the University into the appropriation by the Financial institutions, there is a life-long reliable "iron rice bowl".

Now college students as recipients of higher education, the more will get a "good job" for the value orientation of university study more to get some kind of life skills and meet. This hope to be able to find a satisfactory job through college and university, and happily enjoy the idea of life itself also nothing wrong, it is understandable. However, China's current social system, this work is mainly focused on government agencies, institutions and state-owned large and medium-sized enterprises, which are subject to government control departments or units tend to education, the level of the school in the first place.

In this case, such as "211", "985" University first became the object of pursuit; reading what professional unimportant in these universities, if they are good at this professional is not important, the important thing is brand - which the university's name on the diploma. In turn, local universities, independent colleges and private universities, community what career to make money relatively more professional on the sought after; employment because they are mainly in private enterprises, grass-roots units.

Contractors of higher education, the University itself is a set of teaching, research, and social service agencies of the body itself is also studying higher education. Over the last 
decade, many universities have set up the Institute of Higher Education, and constantly reflect on the value orientation of higher education. Real higher education must be committed to the shaping of human enlightenment and liberation, a highly educated person should not just people received vocational training, nor should it is just a preparation or potential scientists, real Higher education should be given to people is an in-depth understanding of the contemporary human knowledge, for the critical spirit of the believer, for the recognition of civil society and the practitioner of virtue ethics ${ }^{[6]}$ 。

Chinese higher education value changes the traditional concept of the impact of thousands of years, they let several parties involved in higher education there are differences in the target, and one of the local universities as a specific implementation of higher education will face many challenges if it is to address and meet the demands of the value of the parties.

\section{B. Problems faced by local universities on education goals and values}

Since the university as the Illuminati higher education goals and values orientation itself has recognized the "extensive and elegant" is better than "professionals", the spirit of the students responsible, socially responsible point of view, should timely adjust its value orientation. If this college is "211" or "985" universities may resistance unlikely, many things can be tasted. In the country or carried out by the Ministry of Education Excellence engineers education training plan, aims to nurture bring up a large number of innovative capacity, high-quality to adapt to economic and social development needs of all types of engineering and technical personnel, the new industrialization path of development for the country, building an innovative country and this strategy services to promote higher education for social needs personnel training, the attempts of the same type of test, such as within many universities are also Tongji University personnel training model innovation experimental area.

Why such a value orientation remains still in the test? Is that colleges and universities to implement this mode of education there is still resistance; resistance from many aspects, the most important reason is that higher education goals too utilitarian. Since ancient times, the Chinese people in the education overly utilitarian facts are indisputable; on this issue, the first to enter the Chinese missionary and educational missionaries this think so:

Isaac Taylor Hedland, the Beijing Hui Chu College Humanities and God teachers that: "China is an exception actual nation, there is no scientific spirit, just trying to get the results of education, but do not want to acquire useful knowledge through the hard, monotonous learning principle; they want but do not want to get 'method' effort to learn 'reasonable' this is an exaggerated utilitarian approach of the so-called 'practical' knowledge" ${ }^{\text {[7]. }}$

In the lower-level, local universities, independent colleges and private colleges and universities, they do not target college students blitz, suffer from a large number of admissions and retain students, they first have to consider the students of this "utilitarian" value orientation and goal aspirations - after graduation would like to have a "good job".

If such schools do not vote the students, parents opt for a large number of the creation of practical skills and strong professional or curriculum, students may not be complete, in order to retain the students into the school, had to let go recruit professional restrictions to allow students to freely switch between the various professional. In fact, professional it is not "good" and "bad" points, but, in comparison with the employment and income between the different sectors of the society at that time, students and families in the "utilitarian" value orientation, natural produces the so-called "hot professional "and" cold professional ". It can be said, that is such a dilemma faced by the local universities in the educational goals and values.

\section{The problem student unconditional brought to replace the professional}

Part of the local universities, independent colleges and private colleges and universities, in order to attract and retain students in enrollment publicity to freely turn professional commitment into the school, they do this so that the original plan by professional admission become moot. Yibin University, for example, 307 to turn professional in 3424 freshmen enrolled in 2011, 412 students in the 3544 freshmen enrolled in 2012 to turn professional; calculated in proportion to turn professional rate is still too high, both in about $10 \%$

The University has 46 undergraduate majors; they distributed in economics, law, education, literature, science, engineering, and management science and art 8 categories disciplines. However, the 307 students in 2011 to turn professional in 154 transferred to the Specialty Economic Management (financial management, business administration, engineering management, logistics management); similarly, 231 of the 412 students in 2012 to turn professional in name into the economics and management professional, which financial management professional amounted to 143.

Yibin University is a local undergraduate colleges, Yibin Teachers and Yibin Education merged in 2001, the original, previously set up a professional teacher pedagogy class basically; after the merger, in August 2001 the creation of other non-teacher professionals. Education(Teacher Education majors) is the traditional strengths of the school's discipline has accumulated more teachers and teaching resources, students are now fewer, or even only a few individual professional students; contrary, the newly opened financial management class professional, student storm shed, makes teaching this kind is a serious shortage of professional staff and teaching resources. Teachers and teaching resources idle in teacher education in economics and management professional can not be used, however, to increase a tight professional teaching resources invested and the expansion of the faculty on the one hand it takes time, while blindly increase into the high risk; promise as there is a possibility: after a few years, now the hot professional may have turned into a cold professional. 


\section{BASED ON THE BASIS OF THICK, LARGE-CALIBER EDUCATION MODE TASTING}

\section{A. "Thick foundation, large caliber" creative class "attempts in Yibin University}

Like local Yibin II the College, the students admitted that they basically admitted two in Sichuan Province around online a bit; vast majority of these students as mathematics, English, poor grades, resulting in the college entrance examination scores is not high; However, reality intruded completing my school a professional is not willing to let the University of hearts dream away, to be admitted more often than not like a university or a professional but he reported forced the college entrance examination scores are not high. Math, English, two subjects is difficult to make up in a short period of time, resulting in the fear of students learning heavy, in the traditional mode of teaching is easy for them to lack a sense of accomplishment, so that learning and life will become loose and lazy life goal of getting lost; this is a major psychological incentives. A considerable part of them from rural, relatively poor family economic status, are eager to change their own destiny and family status aspirations through higher education; more intense "utilitarian" value orientation.

In the highly developed technology of the information age, any "advanced" knowledge and technology are relatively advanced, even if the students at the university during the master to make a living some vocational skills to find a favorite work in the community, there is no guarantee that the work in the future, has for a long time. Because of this reasoning, Yibin University pumping some of the students in the new students into the school in 2010 to set up an arts innovation classes, sponsored by the Literature \& News Media College, a science innovation classes are the Figures College, Their basic school way: the combination of low-grade general education and basic education, high-grade professional education training model (first-year general education, followed by the third grade corresponding professional development, students through the year to reunderstanding of their own, autonomy to establish their own professional intention, confirmed after the completion of the first year at university learning professional, and professional learning in the class but the class formed the same; implement take the class system, the core curriculum system, flexible educational system, complete a professional core curriculum and repair full credits to graduate), highlight the comprehensive development of the knowledge, ability and quality. The purpose of doing so is to actively explore the educational factor determining student success, build support for local development personnel training new mode. Want to take advantage of high-quality teaching resources, more flexible mode of education management, training highquality top-notch talent. On this basis, in 2012 the expansion of four innovative classes in the arts, science, engineering, administered by the Division; the six innovative classes students have completed the first stage of general education, each chosen professional development into professional development stage. Did not graduate is still in the stage of professional learning, its effectiveness remains to be seen.

\section{B. Implementation of modular curriculum}

(1) Professional core modules: Specific professional living in the core position and personnel training in the basic course has an indispensable role. To teach students the professional who has the knowledge of the principle, fundamental, stability, and methodological.

(2) Liberal core modules: The main purpose is to cultivate students' basic quality requirements make the basis of a society of civilized man, and lifelong learning ability; including ideological and political, sports, foreign languages, and computer foundation and university language.

(3)Expand the module: Its main purpose is to broaden the students 'knowledge, to develop students' scientific literacy and humanistic spirit, optimize the structure of the natural sciences, humanities and social sciences, art and physical life classes, and other areas of the basics, focusing embodies the blend of disciplines, penetration thinking.

(4)Application of modules: Students the basic skills and literacy, and strengthen the practice hands-on skills, communication skills, ability to innovate, harmony ability, career practitioners ability. By training, experiment, trainee, internship, theses (design) constitute.

Reform of the training mode by the pilot, from the dayto-day observation of teaching management, currently operating normally; teachers and students responded well. However, its actual effect, not a year or two years time will be able to be reflected in the effectiveness of the education usually need to wait until after the number of years of graduate students into the community, can be reflected. Whether this taste test has no substantive effect, but at least living in the local dilemma undergraduate institutions, is a kind of hope.

\section{ACKNOWLEDGMENT}

The paper is one of the sub-topics derived from the focus of the research project of Sichuan Education Department, the name: the effectiveness of research-based thick foundation, large-caliber innovative university education mode; Item number 11SA107.

[1] Encyclopaedia Britannica. Volume 8. Beijing: Encyclopedia of China Publishing House 1999, p.72.

[2] Encyclopedia of China (condensed version). Volume 3, Beijing: Encyclopedia of China Publishing House, 1996,p 1497.

[3] ZhaNgchuting. Higher Education Introduction [M]. First edition, Beijing: People's Education Press, 2010, pp 6,101.

[4] WangWei. The educational philosophy at the University of the Modern Church in China-- Liberal liberal education [J] Quest, 2007 (10) , pp 117-229.

[5] LiYang. The fifties faculties Adjustment and Social Change [J]. Open era, 2004 (05) :15-30.

[6] WangJianhua. What is higher education [J]. Higher Education Research, 2012 (09),pp 1-6.

[7] Isaac Taylor Hedland[Americans], Yan Fang translation. CiXi and GuangXu-- Survival Game about Chinese Court [M]. First edition, Beijing: Zhonghua Book Company, 2004。 